\title{
Nevus Composto do Colo Uterino: Relato de Caso.
}

\author{
Compound Nevus of the Uterine Cervix: Case report.
}

Fábio A. S. Lima , Leônidas B. D. Junior,

Suzanne Serruya, João N. Stavale, José Focchi

\begin{abstract}
RESUMO
O nevus composto do colo uterino representa um achado muito raro. Relatos excepcionais de lesões melanocíticas benignas e malignas da endo e exocérvice uterina têm sido publicados. Relatamos o achado ocasional do nevus composto da exocérvice uterina em uma paciente de 47 anos de idade que não apresentava queixas ginecológicas. O diagnóstico foi sugerido pelo exame colposcópico e confirmado à histopatologia. Devido à possibilidade de transformação maligna dessas lesões e à dificuldade de seguimento da paciente, o tratamento foi concluido com a realização de histerectomia total abdominal.
\end{abstract}

PALAVRAS-CHAVE: Nevus. Colo uterino. Colposcopia.

\section{Introdução}

Lesões pigmentadas melanocíticas do colo uterino são muito raras; dentre elas, nevus azul e melanoma maligno têm sido as mais encontradas ${ }^{1}$; são também descritos relatos ocasionais de lentigo benigno e melanose ${ }^{2}$. Nevus composto do colo uterino, caracterizado pela presença de brotamento de células névicas na camada basal e no córion, é um achado extremamente raro e por isso é aqui relatado.

\section{Relato do Caso}

Paciente MSD, 47 anos de idade, raça branca, brasileira, G3P3A0, todos os partos normais e sem queixa ginecológica, foi encaminhada para exame colposcópico devido o achado de lesão escurecida no lábio anterior do colo uterino durante consulta ginecológica de rotina.

Ao exame colposcópico observou-se a presença de lesão escurecida de cor marrom, plana, medindo aproximadamente $4 \times 2 \mathrm{~cm}$, que não se

Departamento de Ginecologia da Universidade Estadual de Medicina do Pará

Departamento de Patologia da Universidade Federal de São Paulo Departamento de Tocoginecologia da Universidade Federal de São Paulo

Correspondência:

Fábio André Souto Lima

Av. Nazaré, 532 sala 108

CEP : 66035- 170

Nazaré - Belém - Pará alterou à aplicação do acido acético a 3\% (Figura 1). O teste de Schiller foi negativo. Vulva e vagina não apresentavam alterações. Foi realizada biópsia do colo uterino em 12 e $1 \mathrm{~h}$. A citologia cérvicovaginal colhida três dias antes da biópsia mostrouse normal, sem atipias celulares.

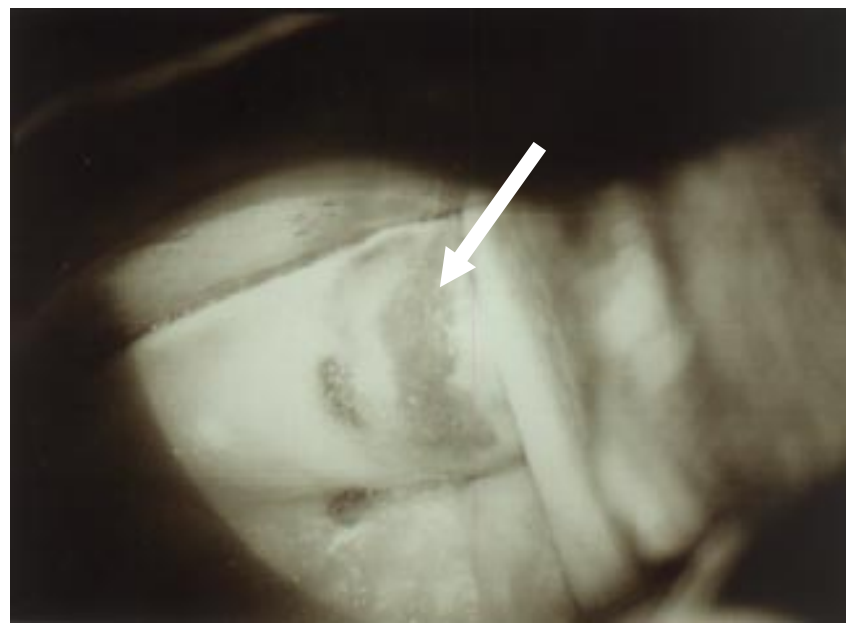

Figura 1 - Colposcopia da exocérvice uterina mostrando lesão pigmentada em 12 e $1 \mathrm{~h}$ $(16 \mathrm{X})$

O material biopsiado foi previamente fixado em formol a 10\%, media 3 e $4 \mathrm{~mm}$ e apresentava superfície de coloração pardo-acizentado. À microscopia ótica mostrou epitélio pavimentoso estratificado queratinizado com a camada basal exibindo brotamentos de células névicas densamente pigmentadas dispostas na zona de junção entre o epitélio e o córion e ainda no córion 
mais superficial (Figuras 2 e 3).

Após o diagnóstico histológico de nevus

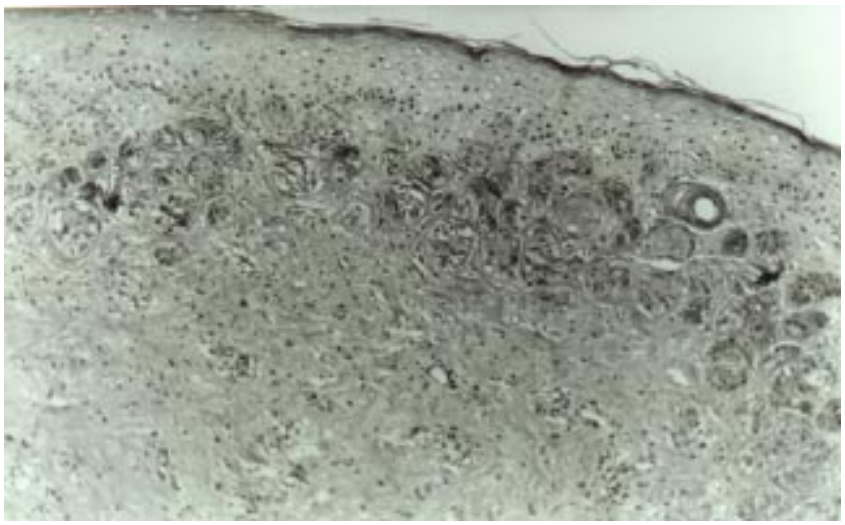

Figura 2 - Fotomicrografia da mucosa exocervical mostrando agrupamento de células névicas na junção da camada basal com o córion e no córion mais superficial. H.E., $160 \mathrm{X}$

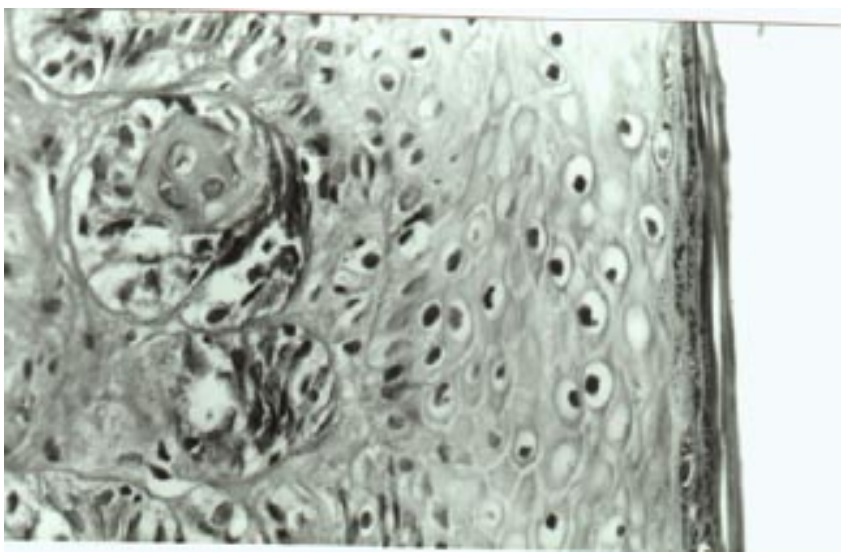

Figura 3 - Fotomicrografia mostrando a junção entre o epitélio exocervical e o córion com ninhos de células névicas com pigmento melânico no citoplasma. H.E., 400X

composto do colo uterino, foi indicada histerectomia abdominal, e o exame anátomopatológico do útero nada acrescentou ao diagnóstico já estabelecido pela biópsia.

\section{Discussão}

As lesões melanocíticas do colo uterino são muito $\operatorname{raras}^{3}$ e mesmo com a citologia cérvicovaginal normal é obrigatório a realização da biópsia para excluir o melanoma cervical, que apesar de também ser muito raro apresenta elevada mortalidade ${ }^{4}$.

A origem dos melanócitos nas lesões pigmentadas do colo uterino ainda não está bem estabelecida. Especula-se sua origem a partir da migração de elementos da crista neural, ou da migração dos melanócitos de áreas mucocutâneas adjacentes, ou ainda em decorrência da transformação do epitélio cervical em um epitélio que se assemelha à epiderme, como resultado de um processo patológico ${ }^{5}$. Nesse sentido, Hytiroglou e Domingo descreveram o desenvolvimento de melanose no colo uterino como conseqüência de crioterapia para displasia cervical ${ }^{6}$.

No caso aqui relatado, a paciente não referia qualquer tratamento ou infecção prévia do colo uterino e seu último exame preventivo tinha sido realizado há mais de 5 anos, o que nos impede de tentar identificar um agente desencadeante para a lesão pigmentada descrita.

A incidência de melanócitos na mucosa cervical uterina é controversa. De acordo com Carinelli et $\mathrm{al}^{7}$, Cid identificou melanócitos em 1,7\% de 466 endocérvices examinadas. Uehara et $\mathrm{al}^{8}$ analisaram 189 úteros de mulheres japonesas e encontraram focos melanocíticos estromais em 28,6 \%. Desconhecemos estudos que demonstrem a incidência de melanócitos no colo uterino de mulheres de nosso meio.

Optamos por realizar a histerectomia abdominal no caso em apreço devido a dificuldade de seguimento da paciente e a possibilidade rara, mas já relatada, do surgimento de melanoma cervical primário conseqüente a melanose préexistente $^{9}$, apesar de Tsukada $^{10}$ ter descrito melanose da vagina e do colo uterino com 13 anos de seguimento sem modificações.

Independente da origem dos melanócitos, o achado de lesões pigmentadas no colo uterino devem ser rapidamente esclarecidas visando-se excluir o melanoma cervical. E a confirmação pela biópsia de uma lesão pigmentada benigna determina o tratamento com excisão ampla e seguimento rigoroso ou mesmo com a histerectomia nos casos de seguimento duvidoso, pois a transformação maligna é uma possibilidade.

\section{SUMMARY}

Compound nevus of the uterine cervix is very rare. Benign and malignant melanotic lesions of endo and exocervix have been rarely documented. The present case of compound nevus in the uterine exocervix was found in a 47-year-old woman without gynecologic complaints. Diagnosis was suspected by colposcopic evaluation and confirmed trough histopathological examination. The treatment was concluded with total abdominal hysterectomy based on the possible malignant transformation of these lesions and the difficult patient follow-up.

KEY WORDS: Nevus. Uterine cervix. Colposcopy. 


\section{Referências bibliográficas}

1- Barter JF, Mazur M, Holloway RW, Hatch KD. Melanosis of the cervix. Case Reports. Gynecol Oncol 1988; 29:101-4.

2- Patel DS, Bhagavan BS. Blue nevus of the uterine cervix. Hum Pathol 1985; 16: 79-86.

3- Walter A. Blue nevus of the endocervix. Case report. Br J Obstet Gynaecol 1982; 89:1059-61.

4- Kristiansen SB, Anderson R , Cohen DM. Primary malignant melanoma of the cervix and review of the literature. Gynecol Oncol 1992; 47: 398-403.

5- Vezzani M, Sola P. La pigmentazione melanica dell" esocervice. Pathologica 1979; 71:657-61.
6- Hytiroglou P, Domingo J. Development of melanosis of uterine cervix after cryotherapy for epithelial dysplasia . Am J Clin Pathol 1990; 93: 802-5.

7- Carinelli S.G, Prat J, Robboy SJ. Blue nevus of the cervix. Tumori 1978; 64: 95-8.

8- Uehara T , Izumo T, Kishi K, Takayama S, Kasuga T. Stromal melanocytic foci ("Blue nevus") in step sections of the uterine cervix. Acta Pathol Jpn 1991; 41: 751-6.

9- Mudge TJ, Johnson J, MacFarlane A. Primary malignant melanoma of the cervix. Br $\mathbf{J}$ Obstet Gynaecol 1981; 88:1257-9.

10- Tsukada Y. Benign melanosis of the vagina and cervix. Am J Obstet Gynecol 1976; 124: $211-2$. 